\title{
Design and Implementation of Fuzzy Logic based Single Phase Inverter using FPGA Controller
}

\author{
S.Kalimuthu Kumar, K.Rajesh, B.Kannapiran, S.Rajendran,K.Vijayakumar
}

\begin{abstract}
The single phase inverter provides continuous AC power supplies without any interrupt.The idea is to serve sinusoidal AC output whose voltage and frequency can be controlled by PWM pulse. The main theme of this concept is to present a new construction of an FPGA based control techniques for inverter. In this proposed system, a PI controller is used to the single phase PWM voltage source inverter. It minimizes periodic distraction resulted from linear load. Simulation provides the results, with reduced harmonics distortion of the output voltage .and innovative technique for including a fuzzy logic controller through a usual sampled pulse-width modulator is reported. The FLC is used to decrease the harmonic distortion and to offer better standard regulation. Simulations are carried out in ALTERA-Quartus II 8.0 software in addition by means of Matlab/Simulink and the results are presented for various control techniques. FPGA controller is preferred for the real time realization of the switching approach, for the most part owing to its larger computation speed which is able to guarantee the precision of the PWM pulse is developed. At the concluding stage the FPGA is used as a PWM generator in order to apply the appropriate signals for inverter switches.
\end{abstract}

Keywords-PWM, FPGA, VHDL, Inverter, PI and Fuzzy logic

\section{INTRODUCTION}

The Pulse Width Modulation (PWM) has at the present a fundamental element of many devices. It is generally acknowledged as control method in most of the electronic appliances. There are a variety of types depending upon structural design and necessity of the system. The Pulse Width Modulation (PWM) has at the present a fundamental part of almost major embedded systems

Revised Manuscript Received on December 05, 2019.

* Correspondence Author

S.Kalimuthu Kumar, Department of biomedical engineering, Kalasalingam Academy of Research and Education, Virudhunagar, India kali.12eee@gmail.com

K.Rajesh, Department of electrical and electronic engineering,

Kalasalingam Academy of Research and Education, Virudhunagar, India. k.rajesh@klu.ac.in

B.Kannapiran, Department of electronics and communication engineering, Dr.Mahalingam College of Engineering \& Technology, Pollachi, India. kannapiran79@gmail.com

S.Rajendran, Department of electrical and electronic engineering, Kalasalingam Academy of Research and Education, Virudhunagar, India. rsrajendran2008@gmail.com

K.Vijayakumar, Department of electrical and electronic engineering, Kalasalingam Academy of Research and Education, Virudhunagar, India. kumark86@gmail.com
It has been generally acknowledged as control method in most of the electronic appliances. These techniques have been widely researched for the duration of many years [2]. There are a variety of types depending upon structural design and necessity of the system. These realizations based on the application type, consumption of the power, types of the switching devices, performance and price criterion all determining the method of providing GATE pulses. The major essential applications of PWM in various application for controlling power converters (chopper, inverter and etc.) representing to E. Koutroulis, A.Dollas and K.Kalaitzakis in [1]. The Solar Photo Voltaic Powered PWM Inverters acts as power converters which widely employ technique of PWM its power converter. These are currently viewing massive reputation for modern applications for the reason that of their greater performance.. A many PWM techniques are utilized to attain desirable voltage and frequency.

Based on N.A. Rahim and Z. Islam in [2], the two methods of Pulse Width modulation scheme selected best possible PWM and carrier PWM. The optimal PWM needs higher computation and therefore additional hardware and for this reason added cost [2] .the other methods of Carrier PWM techniques have require of a carrier signal.

\section{PWM CONTROL OF INVERTER}

Here the four switches have been used to convert Direct current to Alternating current based on the PWM signals given from the PWM generator.[9] The switches may be selected either MOSFET or IGBT based on switching frequency of inverter. Most importantly the PWM pulse is given to IGBT followed by $\mathrm{S} 1$ and $\mathrm{S} 3$ and same pulses are reversed followed by the sequence of $\mathrm{S} 2$ and $\mathrm{S} 4$.If $\mathrm{S} 1$ and $\mathrm{S} 3$ is $\mathrm{ON}$ condition means $\mathrm{S} 2$ and $\mathrm{S} 4$ will be OFF.

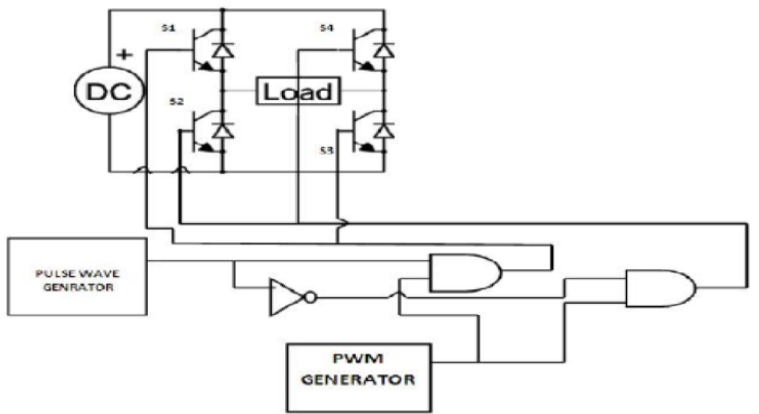

Fig. 1 :PWM control of inverter 


\section{PROJECT DESCRIPTION}

The overall representation of the block diagram is shown in fig 2 which convert DC to AC voltage with reduced harmonics level and stabilized output voltage.

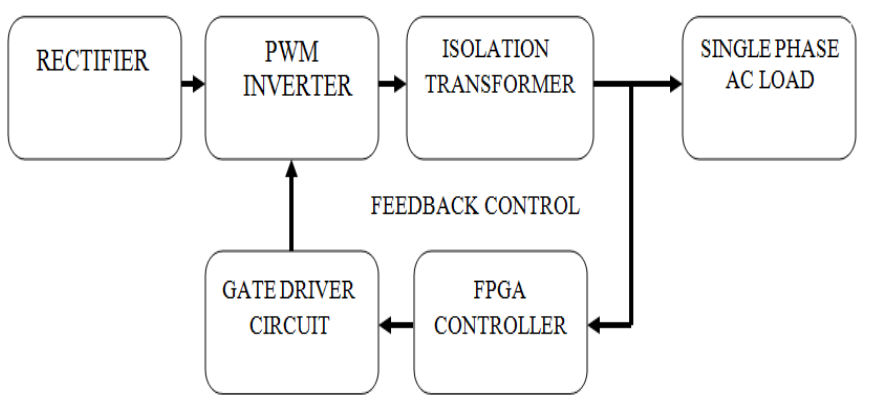

Fig.2: Overall proposed block diagram

The Full wave rectification is used to obtain DC output from a sinusoidal AC. Bridge rectifier with filter is used for the purpose of rectification we use bridge rectifier with filter..The gate pulses are taken from FPGA controller through driver circuit. If any change in output voltage, the error signal fed back to FPGA controller. The GATE driver circuit is used to provide the isolation between the FPGA controller and Power switch circuit .The FPGA controller gives the very lower amplitude GATE pulses which are not sufficient to drive the four Power switches like MOSFET or IGBT. Hence the amplifier parts are included in the GATE driver circuits by means of the transistors. The FPGA controller is one of the scalable controllers which contain the logic gates arranged in form of matrix. The Digital PWM is implemented by help of FPGA controller with in short time and easy to modify the sequence of PWM pulse. Here FPGA ALTERA cyclone family is used to implement the PWM pulses. Hence it is suitable for the low cost small design. The Isolation transformer is used to electrically isolate between the inverter circuit and load. It has symmetrical winding in primary and secondary. Always it blocks reverse flow of current from load side.

\section{PI control}

The Proportional and Integral control is used in Single phase inverter to give the stabilized output. This could be implemented by help of system toolbox in MATLAB. The AC output ( $\mathrm{Vo}$ ) of single phase inverter is fed to the one of the subtract then it produces the error signal (e) .Again the error signal is given to the PI controller which could be generate compensating signal (Cs) then the compensating signal and reference signal are added and it produces the modulating signal(Ms). The PWM pulse is generated by means of this modulating signal.

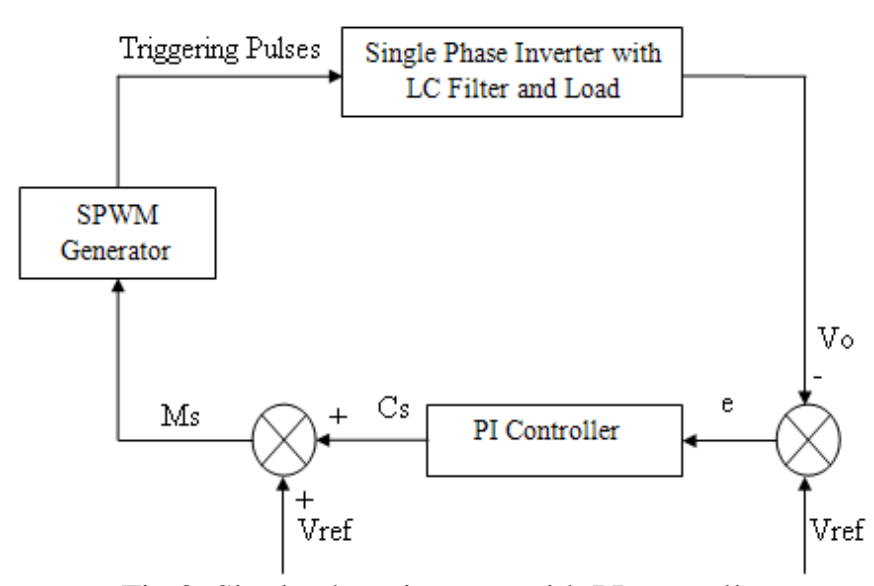

Fig.3: Single phase inverter with PI controller.

The diagram depicts single phase inverter with PI controller which values of proportional constants are $\mathrm{Kp}$ and $\mathrm{Ki}$ are designed using Ziegler-Nicholars tuning technique.

\section{V. fuzzy logic control}

The fuzzy logic controller is rule base decision making algorithm. The most of the non linear system follows the fuzzy control strategy to obtain the appropriate amplitude and to reduce the harmonics of the inverter output.[10]

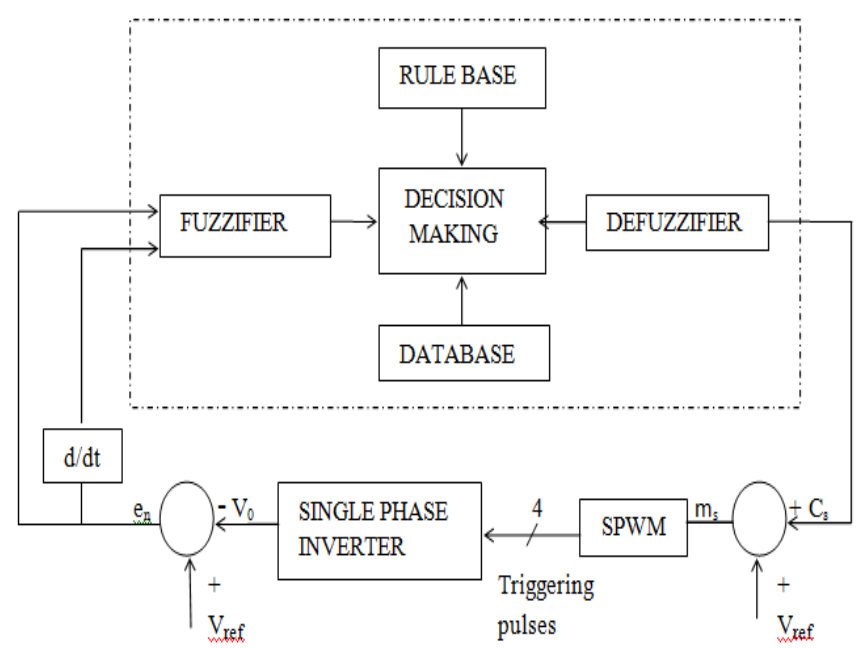

Fig 4: Fuzzy logic control scheme for chosen Single phase PWM inverter

Here the FLC is preferred to generate SPWM gate pulse. It contains the five units. The $7 \mathrm{X} 7$ rule base system has been developed .

\section{Simulation results}

Here the MATLAB /SIMULINK model has been used to develop the simulation model of then single phase PWM inverter 


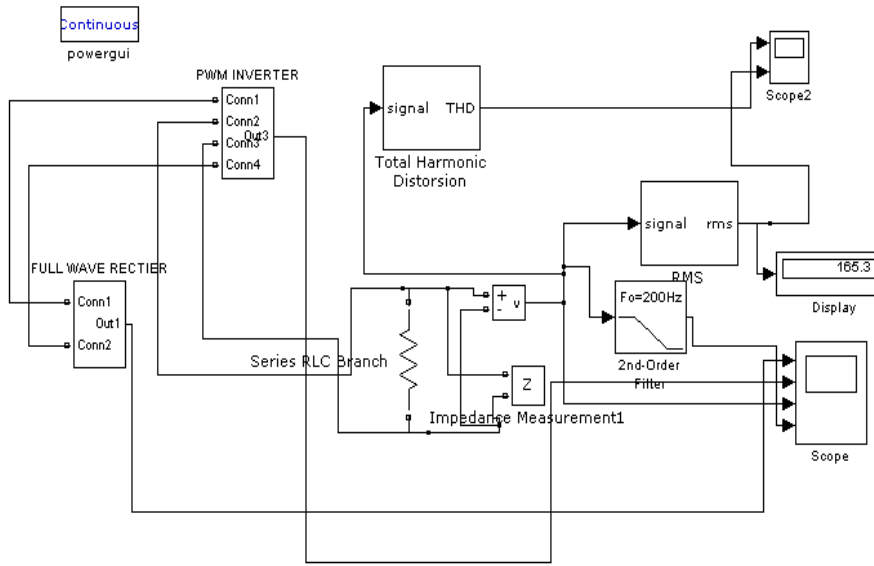

Fig.5 Open loop PWM inverter's output voltage (230V)

The output of the PWM inverter is obtained as a square wave form which amplitude is $230 \mathrm{~V}$ with minimum harmonics and second order filter is used remove the high frequency noise signal generated by high frequency switch.

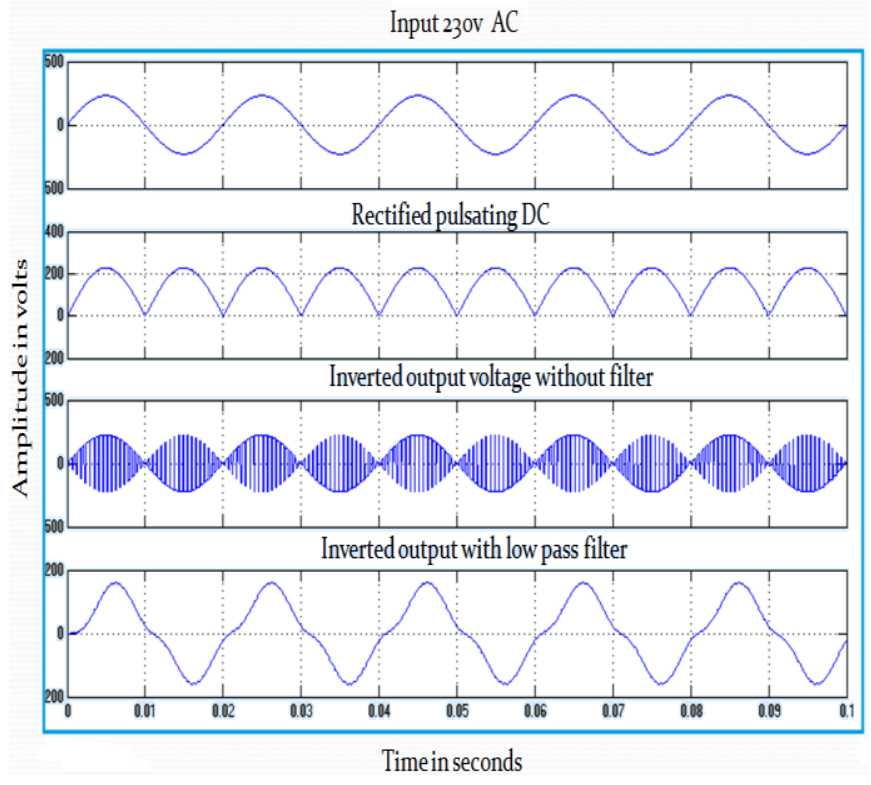

Fig.6 Input and output plot of open loop single phase inverter

Here the input 230 volt $\mathrm{AC}$ is given to rectifier unit which is rectified as pulsating DC again this pulsating is converted to single phase AC wave form with 190 voltage AC

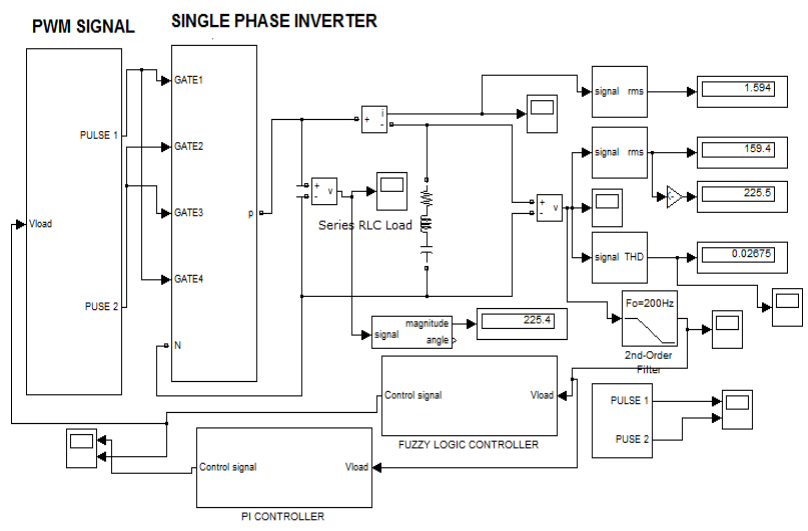

Fig.7: Simulated closed loop control of Inverter
The simulated closed loop control of single phase inverter is controlled by fuzzy logic controller and PI controller to produce the stabilized output voltage. The Gating pulses are generated based on the FLC and PI controller and the RLC load is utilized and two different simulation outputs are taken by using PI controller or Fuzzy logic controller.

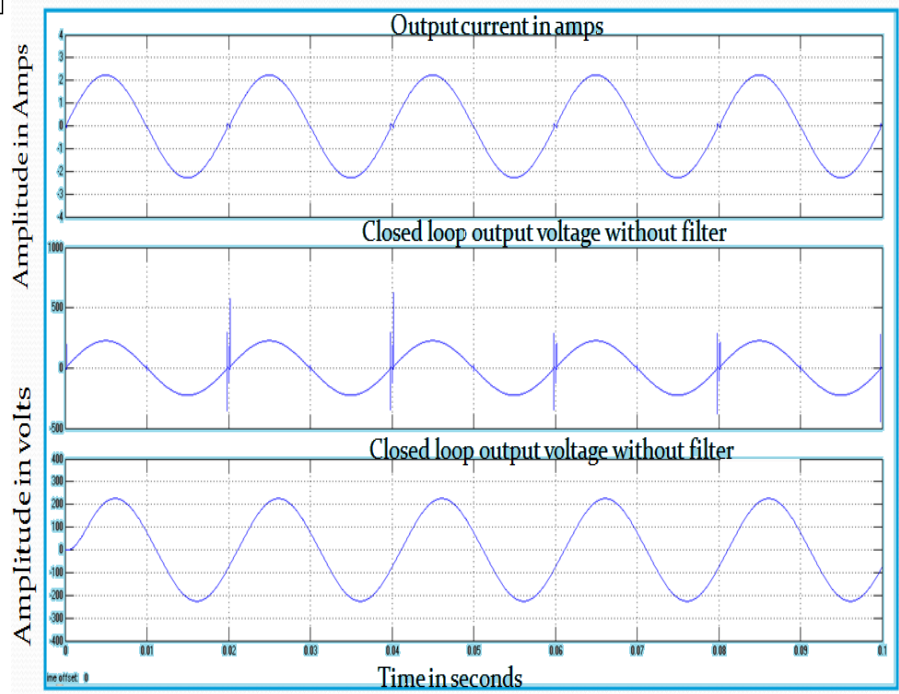

Fig.8: Input and output plot of closed loop single phase inverter

Here the closed loop system is developed to reduce the errors in output and get pure sinusoidal output

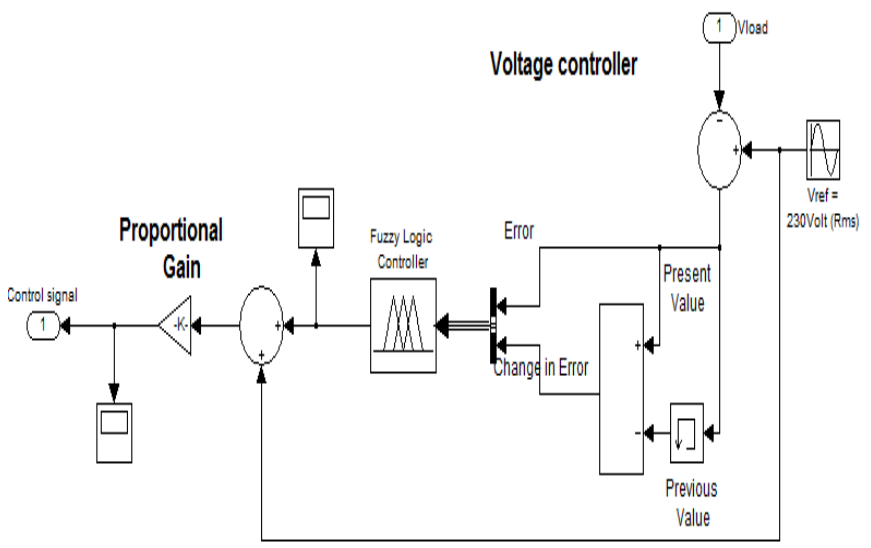

Fig.9: Sub system of Fuzzy controller

Here the reference signal is given as desired sinusoidal wave form as a one input and output voltage is compared with reference signal. The fuzzy logic is generated the compensating signal based on the change in error in the actual output voltage $[7,8]$. By help of compensating signal the modified modulating signal is fed to the PWM generator. It is the responsible to provide proper triggering pulse for the inverter switches. The fuzzy logic based switching strategy has been implemented in ALTERA cyclone II FPGA as $\mathrm{PWM}$ generator which is mentioned in figure 11 


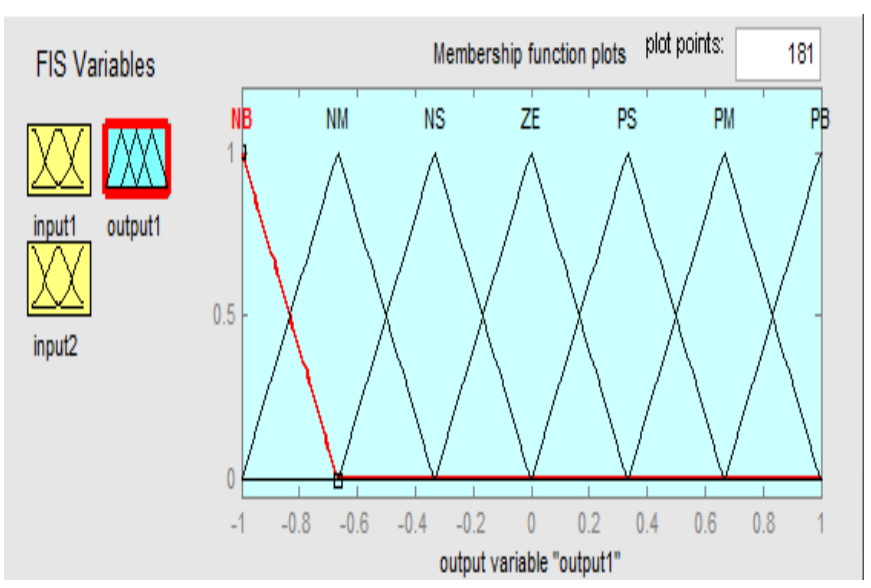

Fig : 10 fuzzy inference system with two input membership function error e, change in error en, compensating signal Cs

\section{FPGA CONTROLLER AS A PWM GENERATOR}

Here the Simulation work carried out by help of ALTERA cyclone II FPGA as a PWM generator it contains on- chip PWM unit to make use of GATE pulses for single phase inverter.[11] Hence Digital PWM has been implemented using the software of Quartus II 8.0 Web Edition.

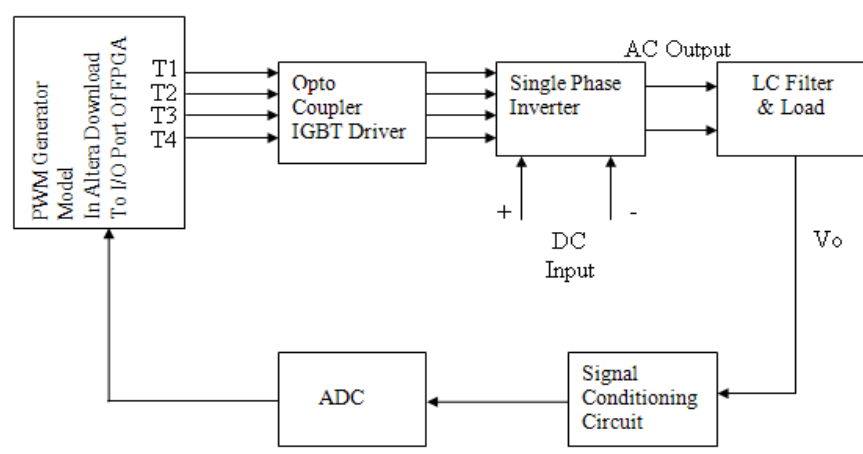

Fig.11: Hardware flow diagram of FPGA based PWM generator

The simulation system model is designed by system generator which is compiled and converted into bit file then it is implemented to FPGA hardware in real time. The pin assignment for each switch is implemented to connect single inverter circuit with FPGA board.

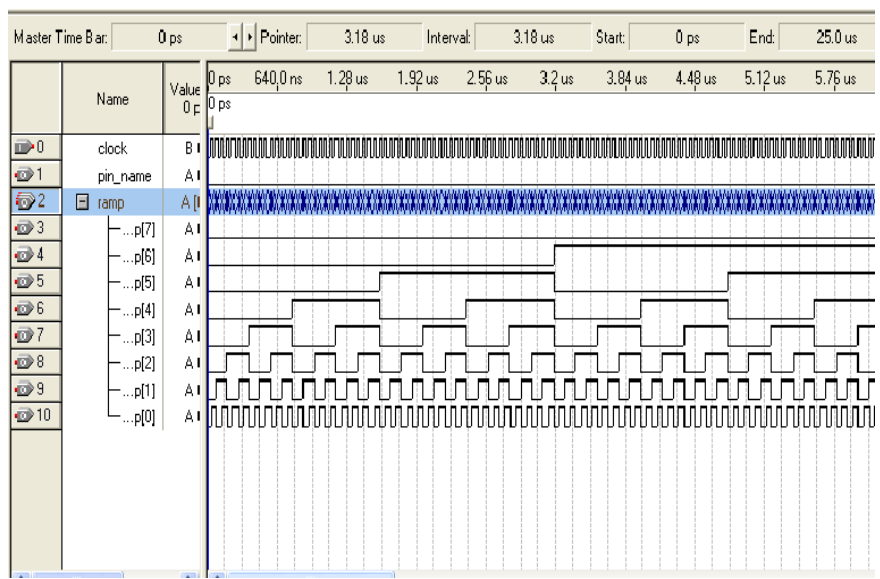

Fig.12 PWM gate pulse generated from FPGA controller. (constant value $=150$, Counter value $0-255$, Duty cycle $50 \%$,time period 1 cycle $=12.8 \mu \mathrm{s}$ )

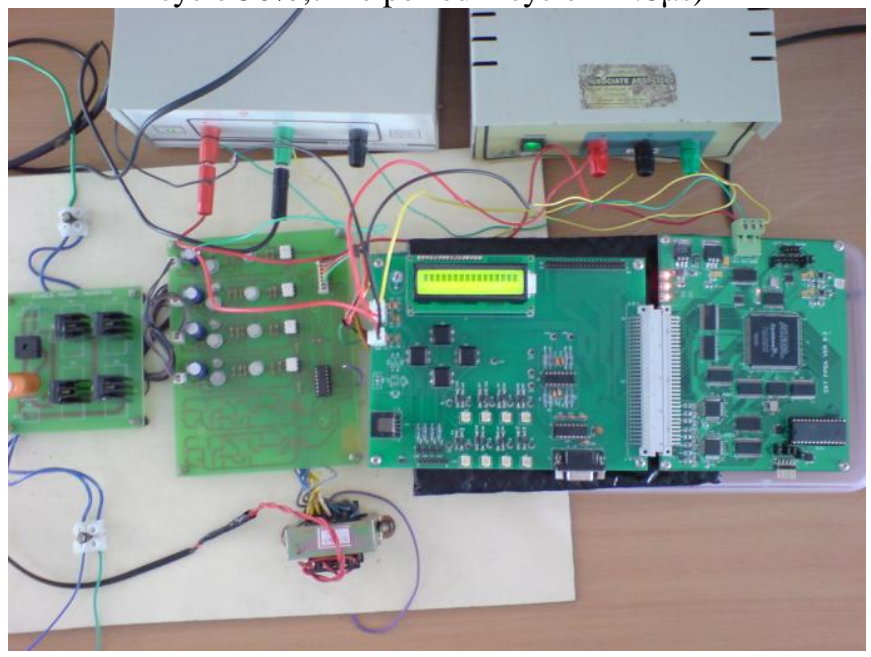

Fig.13 Hardware setup for single phase inverter with control of FPGA ALTERA cyclone family EP1C12Q24OC8 and interfacing board.

\section{CONCLUSION}

The analysis and simulation of single phase inverters have been carried out in the MATLAB simulink environment. The overall THD value is much less from simulation.[11] The closed loop control provides the accurate results, with reduced harmonics distortion of the output voltage. The real time implementation of proposed system has been developed with lighting load. In future we are planned to develop close loop hardware implantation with help of the FPGA controller to the Inverter then to finally verify the proper working of the proposed system with this kit.

\section{REFERENCES}

1. Koutroulis E., Dollas A. and Kalaitzakis K., "High- frequency pulse width modulation implementation using FPGA and CPLD ICs", Journal of Systems Architecture, Vol.52 (2006): pp. 332-344

2. Rahim N.A. and Islam Z., "Field Programmable Gate Array-Based Pulse-Width Modulation for Single Phase Active Power Filter" American Journal of Applied Sciences, Vol.6 (2009): pp. 1742-1747

3. Shih-Liang Jung, Meng-Yueh Chang, Jin-Yi Jyang, Hsiang-Sung Huang, Li-Chia Yeh, and Ying-Yu Tzou'Design and Implementation of an FPGA-Based Control IC for the Single-phase PWM Inverter Used in an UPS”, IEEE Trans. Power Electronics, 1997.

4. Ming Jiang Yiming Yuan "A Simple Variable Integral Gain PI Controller for a Single-phase Inverter”, IEEE Trans. Power Electronics, 2010.

5. B. Ismail, S.Taib MIEEE, A. R Mohd Saad, M. Isa, C. M. Hadzer'Development of a Single Phase SPWM Microcontroller-Based Inverter'IEEE Trans. Power Electronics, 2006.

6. S. M. Ayob, Z. Salam, N. A. Azli Malik E. Elbuluk"Boost Control of A Single Phase Inverter Using Fuzzy Logic", IEEE Trans. Power Electronics, 2009.

7. S. M. Ayob, N. A. Azli and Z. Salam "PWM Inverter Regulation Using Single Input Fuzzy Logic Controller", IEEE Trans. Power Electronics, 2008

8. Kamran Zeb ,Saif Ul Islam ,Waqar Ud Din ,Imran Khan ,Muhammad Ishfaq ,Tiago Davi Curi Busarello ,Iftikhar Ahmad andHee Je Kim ,'Design of Fuzzy-PI and Fuzzy-Sliding Mode Controllers for Single-Phase TwoStages Grid-Connected Transformerless Photovoltaic Inverter" Electronics 2019. 
9. Zeb, K.; Uddin, W.; Khan, M.A.; Ali, Z.; Ali, M.U.; Christofides, N.; Kim, H.J" A Comprehensive Review on Inverter Topologies and Control Strategies for Grid Connected Photovoltaic System". Renew. Sustain. Energy Rev. 2018, 94, 1120-1141.

10. Mohd Tariq, Mohammad Meraj, Abdul Azeem, Ali I. Maswood, Atif Iqbal, and Bharatiraja Chokkalingam" Evaluation of Level-Shifted and Phase-Shifted PWM Schemes for Seven Level Single-Phase Packed U Cell Inverter", CPSS Transactions On Power Electronics And Applications, Vol. 3, No.3, September 2018

11. Chin-Chang Kuo, Ying-Yu Tzou" FPGA Control of a Single-Phase T-Type NPC Grid Inverter for Low THD and Robust Performance"IEEE $3^{\text {rd }}$ International future energy electronics conference and ECCE Asia(IFEEC 2017-ECCE Asia)

\section{AUTHORS PROFILE}

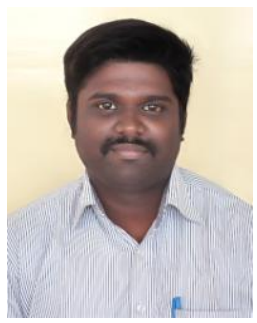

S.Kalimuthu Kumar received his UG degree in Electrical and Electronics Engineering from Anna University, Chennai in 2008 and M.Tech. Degree in Embedded System technology from kalasalingam University, Krishnankoil, in 2011. Since July 2011, he has been working as an Assistant Professor in the Department of Electrical \& Electronics Engineering, Kalasalingam University, Krishnankoil, Virudhunagar District, Tamil Nadu and India. $\mathrm{He}$ published 6 papers in international conferences and journals. He has attended several international conferences and he has been actively involving himself in research since 2014 . He has actively participated in various faculty development programs, symposiums, orientation programs, workshops and national seminars. He completed CLAD (Certified Lab view Associate Developer) in 2018.

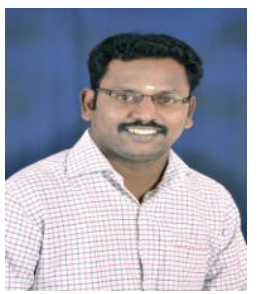

K. Rajesh was born in Rajapalayam, Tamil Nadu, India, in May 1987. He received his UG degree in Electrical Engineering from Anna University, Chennai in 2008 and M.E. degree in Power Systems Engineering from Anna University, Tirunelveli, Tamil Nadu, India, in 2011. Since July 2011, he has been working as an Assistant Professor in the Department of Electrical \& Electronics Engineering, Kalasalingam Tamil Nadu and India University, Krishnankoil, Virudhunagar District,

He has attended several international conferences and he has been actively involving himself in research since 2013. Three of his research papers have been published in international journals and a research paper has been published in national journal. His current research interests include generation expansion planning, energy planning, power system optimization and power system control. He has actively participated in various faculty development programs, symposiums, orientation programs, workshops and national seminars. He has received Teaching Competency Award in the year 2015 and Research Competency Award in the year 2015 \& 2017. He is a Life member of ISTE and Member of IE(I)

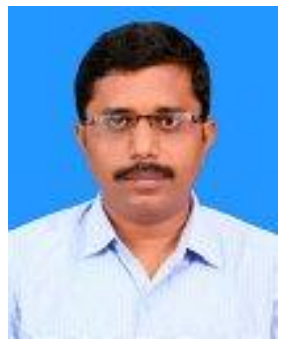

B.Kannapiran is a Professor in department of Electronics and Communication Engineering , Dr.Mahalingam College of Engineering and Technology, Udumalai Road,Pollachi He received his Ph.D. degree in Information and Communication Engineering from Anna University, Chennai in the year 2013. He received his M.E. degree in Applied Electronics from Madurai Kamaraj University in the year 2002. He also received his B.E. degree in Instrumentation and Control Engineering from Madurai Kamaraj University in the year 2001. His research interests include soft computing, fault diagnosis, Biomedical Instrumentation, wireless networks

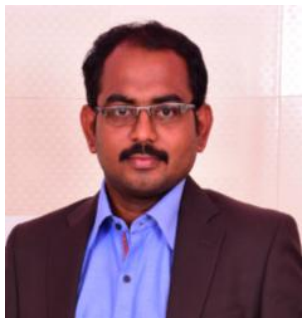

S.Rajendran received his UG degree in Electrical Engineering from Anna University, Chennai with First Class Distinction in 2009 and M.E. degree in Power Electronics and Drives from Anna University, Tiruchirappalli with First Class Distinction in 2011. Now He was pursuing $\mathrm{Ph} . \mathrm{D}$ in the field of reactive powe compensation. Since July 2011, he has been working as an Assistant Professor in the Department of Electrical \& Electronics Engineering, Kalasalingam Academy of Research and Education, Krishnankoil, Virudhunagar District, Tamil Nadu and India. He has attended several international conferences and he has been actively involving himself in research since 2015. His current research interests include reactive power compensation in FACTS devices. He has actively participated in various faculty development programs, symposiums, orientation programs, workshops and national seminars. He has received Teaching Competency Award in the year 2017.He completed CLAD (Certified Lab view Associate Developer) in 2018

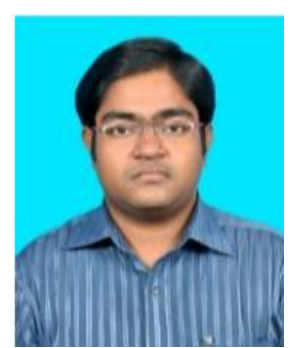

K.Vijaya Kumar received his UG degree in Electrical and Electronics Engineering from Easwari Engineering college, Anna University, Chennai in 2009 and M.E. degree in Power Electronics and Drives from Mepco Schlenk Engineering College, Anna University, Tirunelveli, in 2011. He completed (Distance mode) Master of Business Administration (MBA) from SRM University in 2016. Since July 2011, he has been working as an Assistant Professor in the Department of Electrical \& Electronics Engineering, Kalasalingam University, Krishnankoil, Virudhunagar District, Tamil Nadu and India. He has attended several international conferences and he has been actively involving himself in research since 2012. He published 10 papers in various international conferences, international journals and magazines. His current research interests include Matrix converters, reactive power compensation and optimization techniques in various applications. He has actively participated in various faculty development programs, symposiums, orientation programs, workshops and national seminars. He was working as Business Consultant to Minniyal Private Limited, Start-up Organization initiated under the financia support of National Science \& Technology Entrepreneurship Development Board, DST, Govt. of India, New Delhi. He completed CLAD (Certified Lab view Associate Developer) in 2018 